\title{
MicroRNAs in Cholangiopathies
}

\author{
Steven P. O'Hara • Sergio A. Gradilone • \\ Tetyana V. Masyuk · James H. Tabibian • \\ Nicholas F. LaRusso
}

Published online: 14 June 2014

(C) Springer Science+Business Media New York 2014

\begin{abstract}
Cholangiocytes, the cells lining bile ducts, comprise a small fraction of the total cellular component of the liver, yet perform the essential role of bile modification and transport of biliary and blood constituents. Cholangiopathies are a diverse group of biliary disorders with the cholangiocyte as the target cell; the etiopathogenesis of most cholangiopathies remains obscure. MicroRNAs are small non-coding RNAs that post-transcriptionally regulate gene expression. These small RNAs may not only be involved in the etiopathogenesis of disease, but are also showing promise as diagnostic and prognostic tools. In this brief review, we summarize recent work regarding the role of microRNAs in the etiopathogenesis of several cholangiopathies, and discuss their utility as prognostic and diagnostic tools.
\end{abstract}

Keywords Cholangiocytes - MicroRNAs, cholangiopathies · Cholangiocarcinoma - Polycystic liver disease · Primary biliary cirrhosis · Primary sclerosing cholangitis · Biliary atresia

\section{Introduction}

Cholangiocytes, the epithelial cells lining bile ducts, comprise a small proportion of the total cellular component of the liver, but perform the essential role of bile modification and transport of biliary and blood constituents. Cholangiocytes are the target of a diverse group of disorders collectively

S. P. O’Hara - S. A. Gradilone - T. V. Masyuk ·

J. H. Tabibian · N. F. LaRusso $(\square)$

Division of Gastroenterology and Hepatology, and the Mayo

Clinic Center for Cell Signaling in Gastroenterology,

Mayo Clinic, Rochester, MN 55905, USA

e-mail: larusso.nicholas@mayo.edu referred to as cholangiopathies [1]. Cholangiopathies can be broadly categorized into malignant, immune-mediated, drug- or toxin-induced, infectious, genetic, ischemic, and idiopathic. A common end result for most cholangiopathies is cholestasis, inflammation, fibrosis, and ultimately, the destruction of the bile ducts, yet the etiopathogenesis of most cholangiopathies remains poorly defined. The purpose of this brief review is to present current knowledge and recent discoveries regarding the role of microRNAs in the etiopathogenesis of several cholangiopathies, as well as the diagnostic, prognostic, and therapeutic potential of these small non-coding RNAs in this important group of diseases.

MicroRNAs are one class of small non-coding RNAs that have a demonstrated role in post-transcriptional gene expression. These RNA molecules are transcribed as primary microRNAs that are recognized and processed by the RNase III endonuclease, Drosha. The resultant 60-90 nucleotide precursor microRNA is shuttled from the nucleus in a RAN-GTP/exportin-5-dependent manner, where further cytoplasmic processing by the RNase III endonuclease, Dicer, results in a RNA duplex molecule $\sim 20-23$ nucleotides in length. The microRNA duplex is loaded into the microRNA-associated RNA-induced silencing complex (miRISC) and separated into a functional guide strand and passenger strand. Through complementary base-pairing, the guide strand (mature microRNA) directs the RISC complex to target mRNA for transcriptional suppression or mRNA degradation [2, 3]. Hence, microRNAs are transacting gene regulatory molecules that directly and precisely regulate gene expression and cellular function. It is not surprising; therefore, that altered microRNA expression affects gene expression of several targets underlying the pathobiology of different diseases. Furthermore, differentially expressed microRNAs in diseased tissues or circulating microRNAs in blood or 
Table 1 MicroRNAs, functions, and target genes associated with cholangiopathies

\begin{tabular}{|c|c|c|c|}
\hline miRNA & Function & Target & References \\
\hline \multicolumn{4}{|c|}{ Cholangiocarcinoma } \\
\hline \multicolumn{4}{|l|}{ Upregulated } \\
\hline Let-7a & Cell survival & NF2 & {$[75]$} \\
\hline $\operatorname{miR}-21$ & Apoptosis, proliferation, invasion, metastasis & $\begin{array}{c}\text { MBD2, 15-PGDH/HPGD, } \\
\text { PTEN, PDCD4, TIMP3 }\end{array}$ & {$[12,17,18,76,77]$} \\
\hline $\operatorname{miR}-25$ & Apoptosis & DR4 & {$[78]$} \\
\hline miR-26a & Proliferation, colony formation, tumor growth & GSK-3b & {$[79]$} \\
\hline $\operatorname{miR}-31$ & Proliferation, apoptosis & RASA1 & {$[15]$} \\
\hline $\operatorname{miR}-141$ & Proliferation, circadian rhythm & CLOCK & {$[12]$} \\
\hline $\operatorname{miR}-200 b$ & Chemoresistance & PTPN12 & {$[12]$} \\
\hline $\operatorname{miR}-210$ & Proliferation & Mnt & {$[80]$} \\
\hline $\operatorname{miR}-421$ & Proliferation, migration, colony formation & FXR & {$[81]$} \\
\hline \multicolumn{4}{|c|}{ Downregulated } \\
\hline $\operatorname{miR}-29 b$ & Gemcitabine sensitivity, apoptosis & PIK3R1, MMP-2, Mcl1 & {$[87,11 \bullet \bullet]$} \\
\hline $\operatorname{miR}-34 a$ & Cell cycle, proliferation & $\mathrm{c}-\mathrm{Myc}$ & {$[80]$} \\
\hline $\operatorname{miR}-124$ & Migration, invasion & SMYD3 & {$[16]$} \\
\hline $\operatorname{miR}-138$ & Proliferation, cell cycle, migration, invasion & RhoC & {$[14]$} \\
\hline $\operatorname{miR}-148 \mathrm{a}$ & Proliferation & DNMT-1 & {$[82]$} \\
\hline $\mathrm{miR}-200 \mathrm{~b} / \mathrm{c}$ & Migration, invasion & Rho-kinase2, SUZ12 & [9] \\
\hline miR-204 & EMT, migration, invasion, apoptosis & Slug, Bcl-2 & {$[7,83]$} \\
\hline miR-214 & EMT, metastasis & Twist & {$[8]$} \\
\hline $\operatorname{miR}-320$ & Apoptosis & Mcl-1 & {$[83]$} \\
\hline $\operatorname{miR}-370$ & Proliferation & MAP3K8 & {$[84]$} \\
\hline $\operatorname{miR}-373$ & Epigenetics & MBD2 & {$[85]$} \\
\hline $\operatorname{miR}-376 \mathrm{c}$ & Migration & GRB2 & [13] \\
\hline miR-494 & Proliferation, cell cycle & CDK6 & {$[86]$} \\
\hline \multicolumn{4}{|c|}{ Polycystic liver diseases } \\
\hline \multicolumn{4}{|c|}{ Downregulated } \\
\hline miR-15a & Proliferation, cell cycle & Cdc25a & {$[23]$} \\
\hline $\operatorname{miR}-17$ & Cyst development & Pkd2 & {$[22,29,30]$} \\
\hline \multicolumn{4}{|c|}{ Fibro-obliterative cholangiopathies } \\
\hline \multicolumn{4}{|c|}{ PBC upregulated } \\
\hline miR-506 & Secretion & AE2 & {$\left[49^{\bullet}\right]$} \\
\hline \multicolumn{4}{|c|}{ Biliary atresia upregulated } \\
\hline $\operatorname{miR}-29$ & Epigenetics, cell survival, inflammation & Dnmt3a, Dnmt3b, Igf1, Igf2bp2 & {$\left[60^{\bullet}\right]$} \\
\hline
\end{tabular}

bile have potential as diagnostic and/or prognostic tools. In the following brief review, we discuss recent discoveries regarding microRNAs with respect to cholangiocarcinoma (CCA), polycystic liver diseases, primary biliary cirrhosis (PBC), primary sclerosing cholangitis (PSC), and biliary atresia (BA).

\section{Cholangiocarcinoma}

CCA is a malignancy thought to be derived from cholangiocytes whose incidence and mortality have increased in recent decades [4]. As in other malignancies, microRNA dysregulation in CCA has been associated with the repression of tumor suppressor genes and the upregulation of oncogenes, affecting a myriad of cellular processes and phenotypes including proliferation, apoptosis and stress resistance, migration, invasion, and epithelial-mesenchymal transition (EMT). Indeed, multiple microRNAs are dysregulated in CCA [5, 6] and several have validated molecular targets (Table 1). Much of the recent work has focused on examining molecular targets and pathophysiological outcomes of altered microRNA expression. In the following paragraphs, we summarize the most recent 
reports describing the contribution of microRNAs to the pathobiology of CCA.

Two recent reports have described the functional relevance of diminished microRNA expression in migration and loss of the epithelial phenotype through upregulated EMT-associated transcription factor expression. For example, miR-204 is decreased, as determined by qPCR, in CCA compared to normal adjacent tissue [7]. In vitro, overexpression of miR-204 inhibits migration and invasion of CCA, induces expression of E-cadherin, and reduces the mesenchymal marker, vimentin, likely due to post-transcriptional suppression of Slug, a transcription factor that represses E-cadherin expression. Another microRNA potentially involved in EMT, miR-214, is downregulated in CCA compared to normal tissue; further data stratification has shown that this microRNA is remarkably downregulated in metastatic compared to non-metastatic CCA, and in vitro depletion of miR-214 induces cell migration through direct suppression of the EMT-associated transcription factor Twist [8].

A critical yet poorly understood feature of CCA is the highly aggressive nature and resistance to standard chemotherapy. Utilizing microRNA microarray and validation by RT-qPCR, the miR-200 family members (miR-200a/b/ c/429) were found to be downregulated in perihilar and distal biliary CCA compared to corresponding normal ductal tissue [9]. Both in vitro and in vivo models demonstrate that miR-200b and $-c$ regulate migration and invasion, tumor initiating capacity, 5-FU chemoresistance, and expression of the stem cell marker CD133. Furthermore, these microRNAs target rho-kinase 2 (ROCK2), a downstream mediator of cytoskeleton remodeling, Rho GTPase, and the polycomb repressive complex 2 subunit, SUZ12, a known mediator of breast cancer cell stemness [10]. To directly address microRNAs and CCA chemoresistance, the microRNA expression profile of a gemcitabine resistant cell line $(\mathrm{HuH} 28)$ was recently compared to a sensitive cell line (HuCCT1) [11••]. Bioinformatics analysis and subsequent in vitro experiments revealed three downregulated microRNAs, miR-29b, miR-205, and miR221, and one upregulated microRNA, miR-125a-p, associated with gemcitabine resistance. Potential targets of these microRNAs include PI3KRI and MMP-2, but direct suppression of these targets remains to be confirmed. Altogether, these new findings confirm and expand the previously shown role of miRNAs in response to chemotherapy [12].

Several recent reports reveal that microRNAs likely contribute to CCA survival, growth, and metastasis via regulation of receptor tyrosine kinase and MAPK signaling. One of these microRNAs, mir-376c, is downregulated in CCA cell lines compared to a normal bile duct epithelial cell line [13]. Proteomic analysis and molecular approaches identify GRB2, an essential adaptor for EGFR signaling and Ras/MAPK activation, as a target and potential mediator of the reduced miR-376c cellular phenotype. Additionally, the 'Ras-like' superfamily member, RhoC, is targeted by a microRNA which is reduced in CCA. The reduced expression of miR-138 in CCA correlates with malignant progression of the disease, and in vitro manipulation of miR-138 regulates cell proliferation, G1/S transition, migration, and invasion, likely through direct targeting of RhoC [14]. Another microRNA potentially associated with EGFR signaling and Ras/MAPK activation, miR-31, is upregulated in CCA, targets the negative regulator of Ras, RAS p21 GTPase activating protein 1 (RASA1), and induces increased proliferation and decreased apoptosis via activation of RAS/MAPK signaling [15].

In chronic hepatitis C-related intrahepatic cholangiocarcinoma, miR-124, is downregulated. Overexpression of miR-124 decreased cell migration and invasion [16], likely through the identified target, SMYD3, a histone methyltransferase. Indeed, experimental suppression of SMYD3 represses c-Myc and MMP9 and consequently cell migration and invasion. While dysregulation of miR-21 in CCA was previously described [5], a recent manuscript provides new insight into the functional role for this microRNA in CCA [17]. In O. viverrini-associated CCA, miR-21 is overexpressed and mediates 15-PGDH repression, a physiologic antagonist of COX2/PGE2 signaling. Indeed, miR21-dependent inhibition of 15-PGDH induces PGE2 accumulation. Interestingly, miR-21 expression is induced by PGE2 signaling, suggesting a positive feed-forward loop. Additionally, miR-21 overexpression correlates with decreased expression of the tumor suppressor PDCD4, cell growth and migration in vitro, and shorter survival and lymph node metastasis in $O$. viverrini-associated CCA [18].

When examining intrahepatic tumors, microRNA expression is usually compared to adjacent normal liver tissue; in many cases, the cellular source of this control tissue is not well defined. A standardized approach, including microRNA isolation techniques, and laser capture microdissection of normal adjacent cholangiocytes as control tissue may enhance accurate detection of specific microRNAs altered in CCA compared to normal tissue. Nonetheless, as demonstrated here, the expression of multiple microRNAs is altered in CCA; the challenge remains to determine which if any of these microRNAs drive the malignant phenotype in a given tumor, and whether molecular manipulation can change the course of disease. Furthermore, whether microRNAs can be used as markers of clinical chemosensitivity needs to be explored further. 


\section{Polycystic Liver Diseases}

Polycystic liver disease refers to a group of inherited cholangiopathies resulting from mutation of specific disease-related genes whose products typically localize to primary cilia. Polycystic liver disease seldomly exists as an isolated entity (i.e., autosomal dominant polycystic liver disease, ADPLD), but occurs as an extra-renal manifestation of autosomal dominant (AD-) or autosomal recessive (AR-) polycystic kidney disease (PKD) [19-21]. Several major pathobiological events contribute to hepatic cystogenesis including: (i) mutations in disease-causative genes-PRKCSH and SEC63 (ADPLD-related), PKD1 and PKD2 (ADPKD-related), and PKHD1 (ARPKD-related); (ii) defective remodeling of the ductal plate; and iii) aberrant signaling and cellular function. An increasing number of studies suggest that cystic cholangiocytes and renal epithelial cells are characterized by global changes in microRNA expression patterns which may also contribute to the pathobiology of cystogenesis [22-25].

We found, by microRNA microarray, that the vast majority of microRNAs are downregulated in cystic compared to normal cholangiocytes in an animal model of ARPKD, the PCK rat [23]. In cultured normal rat cholangiocytes, experimental suppression of one of the highly suppressed microRNAs, miR-15a, promotes cell cycle progression and cyst expansion through increased expression of cell division cycle 25A (Cdc25A), an important cell-cycle regulator [23]. Substantial changes in microRNA profiles are also observed in renal epithelia of $\mathrm{PKD} / \mathrm{mhm}$ (cy/+) rats, a model of ADPKD [25]. Importantly, despite the differences between these two animal models, several microRNAs (miR-21, -31, -125, and 196a) are downregulated in both renal and hepatic (i.e., biliary) epithelia, suggesting either shared regulation by disease-associated signaling or a common role for these microRNAs in cystogenesis of renal and hepatic epithelia.

Target prediction algorithms reveal that the known genes involved in cytogenesis are likely under control of multiple microRNAs; some of these microRNA-mRNA target interactions have been evaluated experimentally [26-28]. Indeed, microRNAs contribute to cystogenesis via regulation of polycystic liver disease-related genes, $P k d l$ and $P k d 2$. Differentially expressed in both renal epithelia of $P k d 1^{-1-}$ mice and in cystic cholangiocytes of PCK rats, miR-17 is predicted to target $P K D 2$ mRNA, [23-25, 29] and recent experimental evidence demonstrates that $P k d 2$ is regulated by miR-17 [22, 29, 30]. Moreover, transgenic mice expressing artificial microRNAs to target $P k d l$ developed PKD [31, 32]. These results suggest that abnormally expressed PKD1 and PKD2 as a result of microRNA regulation might contribute to cyst development in both liver and kidney. To date, no experimental data exist regarding regulation of $P K H D 1, P R K S C H$, and SEC63 by microRNAs; however, miR-1, -17, -20, -31, $-106,-130,-194$, and -342 are predicted to target the PKHD1, PRKSCH, and SEC63 transcripts. All of these microRNAs are aberrantly expressed in cystic cholangiocytes [24] and all potentially target disease-associated transcripts, further emphasizing the unexplored potential of post-transcriptional gene regulation in hepatic cystogenesis.

A major event associated with hepatic cystogenesis, as mentioned above, is embryological arrest of ductal plate development, i.e., ductal plate malformation [19, 20, 27, 33-36]. Ductal plate malformation is controlled by a network of signaling pathways (i.e., TGF $\beta 1, \mathrm{WNT}$, and FGF) and transcription factors (e.g., hepatocyte nuclear factors [HNF] $1 \beta, 4$ and 6, homeobox factor [Hhex], CCAAT/ enhancer binding protein $\alpha[\mathrm{C} / \mathrm{EBP} \alpha]$ ), many of which are aberrantly expressed in cystic cholangiocytes [27, 33, 3741]. New findings suggest that microRNAs should be considered as regulators of ductal plate remodeling. Indeed, in zebrafish larvae, specific depletion of miR-30a, a microRNA depleted in human cystic cholangiocytes and renal epithelia $[24,25]$ results in defective bile duct morphogenesis [42]. Whether depletion of ductal plate malformation-associated microRNAs in mammalian systems promotes cystogenesis has yet to be explored; however, several of the known mediators of ductal plate malformation are predicted targets of microRNAs aberrantly expressed in cystic cholangiocytes [24].

Despite interesting observations, the expression, regulation, and role of microRNAs in polycystic liver and kidney diseases are still in an early stage. A comprehensive, integrative genomics approach using both mRNA and microRNA microarrays of the same samples might provide insight into interactions between microRNAs and their targets in cystic cholangiocytes. Such parallel profiling might also help to identify novel mediators of hepatic and/ or renal cystogenesis and reveal novel therapeutic targets.

\section{Fibro-Inflammatory Cholangiopathies}

PBC and PSC are rare but important, chronic, cholestatic liver diseases. Both are characterized by chronic inflammation of the bile ducts, cholestasis, and biliary fibrosis and follow a course that generally progresses to cirrhosis, portal hypertension, and liver failure. BA is also a progressive, fibro-inflammatory, cholestatic liver disease, but unlike PBC and PSC, is a disorder exclusively diagnosed in the neonatal period. BA is the leading indication for pediatric liver transplantation (LT) worldwide [43]. A more comprehensive understanding of the etiology and pathogenesis of these diseases is necessary for the development 
of non-invasive predictive and prognostic biomarkers as well as targeted therapies that improve outcomes.

\section{Primary Biliary Cirrhosis}

PBC is characterized by immune destruction of small intrahepatic cholangiocytes. While the autoimmune nature of disease is established and supported by the highly specific anti-mitochondrial antibodies (AMAs) and autoreactive T-cells, the etiology of PBC remains unknown. Recent analysis of microRNA expression in diseased livers, isolated cells, and patient sera has provided insight into both the molecular pathogenesis of disease and the utility of microRNAs as biomarkers of disease.

A microRNA microarray approach was recently utilized to gain preliminary insight into the potential role of microRNAs in the etiopathogenesis of PBC. Thirty-five microRNAs were differentially expressed (11 upregulated, and 24 downregulated) in PBC compared to normal tissue, a subset of which were validated by real-time PCR (RTPCR) [44•]. A bioinformatics approach was then used to characterize the predicted cellular phenotype; many of the predicted upregulated genes (i.e., predicted targets of downregulated microRNAs) clustered into the biological processes of inflammatory response, calcium ion homeostasis, and negative regulation of hormone secretion. While this study demonstrated that there are differences in the microRNA profiles between PBC and normal livers, further investigations are needed to identify cell types and pathways involved in and modified by this altered microRNA expression profile, and whether the observations are related to cirrhosis in general or PBC specifically.

A key biological feature of PBC is diminished secretinstimulated bicarbonate secretion and decreased biliary expression of anion exchanger 2 (AE2/SLC4A2) [45, 46]. $\mathrm{AE} 2$ is a $\mathrm{Cl}-\mathrm{HCO} 3-$ exchanger on hepatocyte canalicular and cholangiocyte apical membranes that controls intracellular $\mathrm{pH}$ and promotes alkalization of bile [47, 48]. It was recently proposed that microRNAs may contribute to the observed AE2 suppression in PBC patients [49•]. Target prediction algorithms identified the AE2 transcript as a target of miR-506, previously identified as upregulated in PBC tissue [44•]. Cell culture-based functional analyses demonstrated that mir-506 targets the $3^{\prime} \mathrm{UTR}$ of AE2, decreases AE2 protein expression, and modulates anion exchange. Moreover, isolated human PBC cholangiocytes exhibit increased mir-506 expression and diminished AE2 activity; transfection of these cells with a mir-506 antagomir rescues AE2 activity. Hence, this series of experiments demonstrates the logical extension from highthroughput identification of candidate microRNAs through hypothesis-driven validation of target-gene function in a specific cell type.
The microRNA expression profile in peripheral blood mononuclear cells (PBMCs) from patients with PBC has also been assessed by microarray [50]. This was initially performed using microarray and followed by RT-PCR, which validated six microRNAs, miR-15, -20a, -106b, $-140,-181 \mathrm{a}$, and -3654 , as being altered in PBC compared to healthy controls. A bioinformatics approach identified predicted targets which were categorized into GO biological processes, and pathway analyses were performed. A microRNA-gene interaction network placed three upregulated microRNAs (miR-20a, -106b, and -93) at the core of a gene network potentially regulating endocytosis, MAPK, TGF-b, Wnt, and p53 signaling pathways. The microRNA expression profile of sera from a small cohort of patients with PBC has also been assessed [51]. Based on Illumina deep sequencing, expression of two microRNAs, miR-505 and miR-197-3p, was decreased in PBC patients compared to normal healthy and disease controls. While these highthroughput approaches can identify putative molecular pathways affected in disease, these observations and predictions have yet to be validated in cell culture and animal models of disease or evaluated for relevance in human disease.

\section{Primary Sclerosing Cholangitis}

PSC is a progressive cholangiopathy characterized by biliary tract inflammation and fibrosis, no effective pharmacotherapy, and a median LT-free survival of 12 years [52, 53]. CCA is a feared complication of this disease and occurs in approximately $10 \%$ of PSC patients within 10 years of initial PSC diagnosis [54, 55]. A better understanding of the pathogenesis and identification of new therapeutic molecular targets are needed. Currently, no studies have addressed the role of microRNAs in the etiology or pathogenesis of PSC. To date, two manuscripts address the utility of microRNA expression profiles in bile as a diagnostic tool for CCA detection [56••, 57], yet only one utilizes PSC patients without CCA as a control [56••]. The role of microRNAs as a tool for detection of CCA in PSC patients is discussed below.

\section{Biliary Atresia}

BA remains an idiopathic disorder, but several mechanisms, including genetic, infectious, immunologic, and toxin-induced have been implicated and may be interrelated [58]. Regardless of type, BA universally progresses to fibro-obliteration of the extrahepatic bile ducts [58, 59]. Early diagnosis of BA is essential for good outcomes, and once established, the Kasai procedure (hepatoportoenterostomy) should be performed promptly in an attempt to relieve biliary obstruction and restore bile flow [58]. 
Postoperatively, patients must be followed longitudinally as $50 \%$ will gradually develop chronic liver disease and ultimately require LT. Given that early diagnosis portends better operative and survival outcomes, less-invasive biomarkers to diagnose and later to follow liver disease progression are needed. To this end, genetic, meta bolomic, proteomic, and gene expression markers, including microRNAs have been investigated.

Initial inquiries into the role of microRNAs in BA etiopathogenesis were performed using the rhesus rotavirus (RRV)-BALB/c model of biliary atresia. MicroRNA microarray of liver explants demonstrated temporal alterations of microRNAs from $0,3,8$, and 14 days postinfection [60 ]. The mir-29 family of microRNAs (miR29a and miR-29b-1) was upregulated 8 and 14 days postinfection. Intriguingly, this is in contrast to the decreased miR-29 expression observed in hepatic stellate cells in rodent models of fibrosis and in livers from patients with advanced liver fibrosis [61]. Indeed, overexpression of miR-29a in the RRV model was observed by in situ hybridization throughout the liver lobule, in hepatocytes and cholangiocytes, with increased expression in periportal regions. In vivo suppression of miR-29, using intraperitoneal injection of antisense oligonucleotides, results in a concomitant increase in DNA methyltransferases (Dnmt3a and Dnmt3b) as well as Igf1 and Igf2bp2, which were subsequently confirmed as targets of miR-29 using luciferase reporter assays. Whether manipulation of miR-29 in the RRV model of BA modifies disease course has yet to be determined. Nonetheless, this series of experiments demonstrates that the expression of a single microRNA or family of microRNAs may perform distinct functions depending on cell type.

A recent high-throughput microRNA expression array on RNA isolated from extrahepatic bile duct (EHBD) tissue of RRV-BALB/c mice revealed a similar overall pattern of microRNA repression [62・•]. In contrast, however, miR-29b (but not miR-29a) was elevated in EHBD tissue. Despite the discrepancy in mir-29a expression between this study and the previous study, which may be due to the tissue source of RNAs, the results support a possible functional role for elevated miR-29 family members in BA pathogenesis. To predict possible functional roles of altered microRNAs, an integrative genomics approach was performed. A data set of upregulated mRNAs, identified by microarray [63], revealed 14 potential target genes harboring microRNA target sequences corresponding to eight microRNAs (miR-30b/c, -133a/b, -195, -200a, -320, and -365) consistently decreased at times of obstruction (7 days) and atresia (14 days). The predicted target genes had associations with the biological processes of hematology, inflammation, and organ and tissue development. This robust integrative genomics approach serves as a hypothesis-generating data set that is in need of validation by cell culture and animal models of disease. While predicted off-target effects of microRNA manipulation remains a concern in RNA-based therapeutics, this integrated data set demonstrates a potential advantage of RNAi-based therapeutics in that a single or few microRNAs, appropriately targeted to a specific cell type, may alter expression of gene clusters within signaling pathways and processes associated with disease.

\section{Diagnostic, Prognostic, and Therapeutic Prospects}

Early detection of CCA is challenging, and disappointingly few CCAs are detected while still amenable to curative surgical intervention. The current surveillance modalities for high-risk groups for CCA, including PSC, have limited sensitivity for the detection of CCA $[64,65]$ and establishing an accurate diagnosis of cancer is often difficult [66]. This can result in a delayed diagnosis of CCA, which can compromise therapeutic options and patient outcome $[67,68]$. Thus, improvement in diagnostic methods for CCA is needed, and in this regard, microRNAs found in bile have shown promise [56•• 57]. Recently, Shigehera et al. assessed bile obtained from patients with CCA, gall bladder cancer, or choledocolithiasis, by small RNA library sequencing and microRNA RT-PCR-based arrays; one microRNA, miR-9, demonstrated the most reliable diagnostic specificity and sensitivity for biliary tract cancer [57]. A more recent analysis suggested that the quality and quantity of microRNAs derived from biliary exosomes are more predictable than those derived from whole bile [56••]. Using a highly standardized approach, 11 microRNAs were analyzed for their utility as biomarkers for CCA in a patient cohort of $46 \mathrm{CCA}$ and 50 control patients (including 13 with PSC but no CCA). It was determined that the combinatorial use of five microRNAs (miR-16, -486-3p, -484, $1274 \mathrm{~b}$, and -191) had the best predictive value since together there were rarely false positive classifications, and because they were complimentary in making true-positive classifications. The 5-microRNA panel performed better than CA 19-9 in sensitivity (71 vs. $58 \%$ ) and was thus proposed to potentially facilitate earlier CCA detection. Ultimately, a combinatorial approach using serum CA 19-9 and bile microRNAs may improve patient outcomes by allowing more reliable, earlier detection and become a valuable diagnostic tool, particularly for those patients at high risk of CCA, e.g. PSC patients.

MicroRNAs have also recently shown promise as prognostic tools for CCA progression. In a retrospective study, the overexpression of miR-151-3p or the downregulation of miR-126 were identified as potential prognostic markers for CCA progression. Interestingly, these two 
microRNAs were the only independent predictors of survival in that small group of patients [69॰]. In a different study, the overexpression of miR-21 was associated with poor 3-year survival [70]. The prognostic value of these microRNAs may be important for the stratification of patients for clinical trials as well as in identifying which might benefit from adjuvant therapies.

As with CCA, the development of an inexpensive, relatively non-invasive, sensitive, and specific diagnostic marker that is feasible in routine practice is still needed for BA. In a recent study, serum microRNAs were assessed for their utility as a diagnostic tool to differentiate BA from other forms of neonatal hyperbilirubinemia [71]. A microRNA array was performed on sera from BA patients and age- and sex-matched indeterminate cholestasis controls. The microRNAs of the miR-200b/429 cluster displayed good diagnostic properties, with sensitivity and specificity values ranging from 71 to $92 \%$, comparable to serum $\gamma$-glutamyl transpeptidase. This study serves as a proof-ofprinciple for the use of microRNA detection as a sensitive non-invasive diagnostic biomarker in BA. Moreover, combination of microRNA analysis with other biochemical parameters from serum may facilitate early detection and thus early intervention, and improved patient outcome.

The utility of microRNAs as a primary diagnostic tool for PBC, PSC, and polycystic liver disease is less clear as the current approaches are accurate and efficient. For example, PBC can generally be diagnosed by positive AMA detection (or if needed, liver biopsy) and a cholestatic serum liver profile, PSC by cholangiography and a cholestatic profile (or liver biopsy in indeterminate or small duct PSC cases), and polycystic liver disease by physical examination coupled with abdominal imaging. Thus, the potential utility of microRNA analyses in these cholangiopathies lies in their potential to serve as prognostic tools to detect more aggressive forms of the disease or those that will favorably respond to therapy; this is an area lacking published data.

\section{Conclusions}

While showing promise, and having various potential applications, the role of microRNAs as diagnostic, predictive, or prognostic biomarkers for cholangiopathies requires further investigation, including replication of previous findings in larger cohorts of patients. Furthermore, stringent protocol standardization with respect to the source of RNA, purification and amplification procedures, and microRNA expression normalization will be needed. Additionally, the search for more effective therapies for cholangiopathies is an intensive area of research, and the in vivo manipulation of microRNA expression is a promising approach. An attractive feature of microRNA therapy is the potential to target multiple mediators of pathways that concertedly regulate cellular processes. Ideally, chemically modified microRNA mimics would restore the expression of a diminished microRNA (replacement therapy), while antisense modified oligonucleotides would inhibit an upregulated microRNA (microRNA inhibition therapy) and restore cellular homeostasis. The issue of RNA stability in vivo has been addressed through the use of chemically modified oligonucleotides [72, 73]; however, the critical hurdle of targeted delivery of these oligonucleotides remains an issue. Many advances in oligonucleotide delivery have been realized since the discovery of RNAi [74], yet whether any of these delivery methods can be utilized to target cholangiocytes remains to be investigated. Moreover, the mechanisms underlying microRNA dysregulation remain understudied. Multiple mechanisms may account for alteration of microRNA expression, including transcription or epigenetic, RNA degradation, and altered microRNA biogenesis or nuclear transport. Understanding why microRNAs are dysregulated could aid in the identification of therapeutic targets and build a more versatile set of tools to restore normal expression and function of these important non-coding RNAs [12, 41, 75-87].

Acknowledgments This work was supported by National Institutes of Health Grants AI089713 (to S.P.O.), DK57993 (to N.F.L), the Mayo Foundation, PSC Partners Seeking a Cure, and the Mayo Clinic Center for Cell Signaling in Gastroenterology (P30DK084567).

\section{Compliance with Ethics Guidelines}

Conflict of Interest Steven O'Hara, Sergio Gradilone Tatyana Masyuk, James Tabibian, and Nicholas LaRusso declare that they have no conflicts of interest.

Human and Animal Rights and Informed Consent This article does not contain any studies with human or animal subjects performed by any of the authors.

\section{References}

Papers of particular interest, published recently, have been highlighted as:

- Of importance

•- Of major importance

1. Lazaridis KN, Strazzabosco M, Larusso NF (2004) The cholangiopathies: disorders of biliary epithelia. Gastroenterology 127:1565-1577

2. Bartel DP (2009) MicroRNAs: target recognition and regulatory functions. Cell 136:215-233

3. Garzon R, Marcucci G, Croce CM (2010) Targeting microRNAs in cancer: rationale, strategies and challenges. Nat Rev Drug Discov 9:775-789 
4. Razumilava N, Gores GJ (2014) Cholangiocarcinoma. Lancet. doi:10.1016/S0140-6736(13)61903-0

5. Munoz-Garrido P, Garcia-Fernandez de Barrena M, Hijona E, Carracedo M, Marin JJ, Bujanda L, Banales JM (2012) MicroRNAs in biliary diseases. World J Gastroenterol 18:6189-6196

6. Natarajan SK, Smith MA, Wehrkamp CJ, Mohr AM, Mott JL (2013) MicroRNA function in human diseases. Med Epigenetic 1:106-115

7. Qiu YH, Wei YP, Shen NJ, Wang ZC, Kan T, Yu WL, Yi B, Zhang YJ (2013) miR-204 inhibits epithelial to mesenchymal transition by targeting slug in intrahepatic cholangiocarcinoma cells. Cell Physiol Biochem 32:1331-1341

8. Li B, Han Q, Zhu Y, Yu Y, Wang J, Jiang X (2012) Downregulation of miR-214 contributes to intrahepatic cholangiocarcinoma metastasis by targeting Twist. FEBS J 279:2393-2398

9. Peng F, Jiang J, Yu Y, Tian R, Guo X, Li X, Shen M, Xu M, Zhu F, Shi C, Hu J, Wang M, Qin R (2013) Direct targeting of SUZ12/ ROCK2 by miR-200b/c inhibits cholangiocarcinoma tumourigenesis and metastasis. Br J Cancer 109:3092-3104

10. Iliopoulos D, Lindahl-Allen M, Polytarchou C, Hirsch HA, Tsichlis PN, Struhl K (2010) Loss of miR-200 inhibition of Suz12 leads to polycomb-mediated repression required for the formation and maintenance of cancer stem cells. Mol Cell 39:761-772

11. • Okamoto K, Miyoshi K, Murawaki Y (2013) miR-29b, miR205 and miR-221 enhance chemosensitivity to gemcitabine in HuH28 human cholangiocarcinoma cells. PLoS One 8:e77623. MicroRNA expression profiling of a gemcitabine resistant cell line $(\mathrm{HuH28})$ vs. a sensitive cell line $(\mathrm{HuCCT1})$ revealed three downregulated microRNAs and one upregulated microRNA associated with chemotherapeutic resistance.

12. Meng F, Henson R, Lang M, Wehbe H, Maheshwari S, Mendell JT, Jiang J, Schmittgen TD, Patel T (2006) Involvement of human micro-RNA in growth and response to chemotherapy in human cholangiocarcinoma cell lines. Gastroenterology 130:2113-2129

13. Iwaki J, Kikuchi K, Mizuguchi Y, Kawahigashi Y, Yoshida H, Uchida E, Takizawa T (2013) MiR-376c down-regulation accelerates EGF-dependent migration by targeting GRB2 in the HuCCT1 human intrahepatic cholangiocarcinoma cell line. PLoS One 8:e69496

14. Wang Q, Tang H, Yin S, Dong C (2013) Downregulation of microRNA-138 enhances the proliferation, migration and invasion of cholangiocarcinoma cells through the upregulation of RhoC/p-ERK/MMP-2/MMP-9. Oncol Rep 29:2046-2052

15. Hu C, Huang F, Deng G, Nie W, Huang W, Zeng X (2013) miR31 promotes oncogenesis in intrahepatic cholangiocarcinoma cells via the direct suppression of RASA1. Exp Ther Med 6:1265-1270

16. Zeng B, Li Z, Chen R, Guo N, Zhou J, Zhou Q, Lin Q, Cheng D, Liao Q, Zheng L, Gong Y (2012) Epigenetic regulation of miR124 by hepatitis $\mathrm{C}$ virus core protein promotes migration and invasion of intrahepatic cholangiocarcinoma cells by targeting SMYD3. FEBS Lett 586:3271-3278

17. Lu L, Byrnes K, Han C, Wang Y, Wu T (2014) MiR-21 targets 15-PGDH and promotes cholangiocarcinoma growth. Mol Cancer Res. doi:10.1158/1541-7786

18. Chusorn P, Namwat N, Loilome W, Techasen A, Pairojkul C, Khuntikeo N, Dechakhamphu A, Talabnin C, Chan-On W, Ong CK, Teh BT, Yongvanit P (2013) Overexpression of microRNA21 regulating PDCD4 during tumorigenesis of liver fluke-associated cholangiocarcinoma contributes to tumor growth and metastasis. Tumour Biol 34:1579-1588

19. Chandok N (2012) Polycystic liver disease: a clinical review. Ann Hepatol 11:819-826

20. Gevers TJ, Drenth JP (2013) Diagnosis and management of polycystic liver disease. Nat Rev Gastroenterol Hepatol 10(2):101-108
21. Masyuk T, Masyuk A, Larusso N (2009) Cholangiociliopathies: genetics, molecular mechanisms and potential therapies. Curr Opin Gastroenterol 25:265-271

22. Bhatt K, Mi QS, Dong Z (2011) microRNAs in kidneys: biogenesis, regulation, and pathophysiological roles. Am J Physiol Renal Physiol 300:F602-F610

23. Lee SO, Masyuk T, Splinter P, Banales JM, Masyuk A, Stroope A, Larusso N (2008) MicroRNA15a modulates expression of the cellcycle regulator $\mathrm{Cdc} 25 \mathrm{~A}$ and affects hepatic cystogenesis in a rat model of polycystic kidney disease. J Clin Invest 118:3714-3724

24. Masyuk T, Masyuk A, Larusso N (2009) MicroRNAs in cholangiociliopathies. Cell Cycle 8:1324-1328

25. Pandey P, Brors B, Srivastava PK, Bott A, Boehn SN, Groene HJ, Gretz N (2008) Microarray-based approach identifies microRNAs and their target functional patterns in polycystic kidney disease. BMC Genomics 9:624

26. Park EY, Woo YM, Park JH (2011) Polycystic kidney disease and therapeutic approaches. BMB Rep 44:359-368

27. Wills ES, Roepman R, Drenth JP (2014) Polycystic liver disease: ductal plate malformation and the primary cilium. Trends Mol Med 20:261-270

28. Strazzabosco M, Somlo S (2011) Polycystic liver diseases: congenital disorders of cholangiocyte signaling. Gastroenterology 140:1855-1859, 1859 e1851.

29. Sun H, Li QW, Lv XY, Ai JZ, Yang QT, Duan JJ, Bian GH, Xiao Y, Wang YD, Zhang Z, Liu YH, Tan RZ, Yang Y, Wei YQ, Zhou Q (2010) MicroRNA-17 post-transcriptionally regulates polycystic kidney disease-2 gene and promotes cell proliferation. Mol Biol Rep 37:2951-2958

30. Tran U, Zakin L, Schweickert A, Agrawal R, Doger R, Blum M, De Robertis EM, Wessely O (2010) The RNA-binding protein bicaudal $\mathrm{C}$ regulates polycystin 2 in the kidney by antagonizing miR-17 activity. Development 137:1107-1116

31. Wang E, Hsieh-Li HM, Chiou YY, Chien YL, Ho HH, Chin HJ, Wang CK, Liang SC, Jiang ST (2010) Progressive renal distortion by multiple cysts in transgenic mice expressing artificial microRNAs against Pkd1. J Pathol 222:238-248

32. Schena FP, Serino G, Sallustio F (2014) MicroRNAs in kidney diseases: new promising biomarkers for diagnosis and monitoring. Nephrol Dial Transplant 29:755-763

33. Raynaud P, Carpentier R, Antoniou A, Lemaigre FP (2011) Biliary differentiation and bile duct morphogenesis in development and disease. Int J Biochem Cell Biol 43:245-256

34. Temmerman F, Missiaen L, Bammens B, Laleman W, Cassiman D, Verslype C, van Pelt J, Nevens F (2011) Systematic review: the pathophysiology and management of polycystic liver disease. Aliment Pharmacol Ther 34:702-713

35. Gunay-Aygun M (2009) Liver and kidney disease in ciliopathies. Am J Med Genet C Semin Med Genet 151C:296-306

36. Desmet VJ (1998) Ludwig symposium on biliary disorders: part I. Pathogenesis of ductal plate abnormalities. Mayo Clin Proc 73:80-89

37. Decaens T, Godard C, de Reynies A, Rickman DS, Tronche F, Couty JP, Perret C, Colnot S (2008) Stabilization of beta-catenin affects mouse embryonic liver growth and hepatoblast fate. Hepatology 47:247-258

38. Raynaud P, Tate J, Callens C, Cordi S, Vandersmissen P, Carpentier R, Sempoux C, Devuyst O, Pierreux CE, Courtoy P, Dahan K, Delbecque K, Lepreux S, Pontoglio M, Guay-Woodford LM, Lemaigre FP (2011) A classification of ductal plate malformations based on distinct pathogenic mechanisms of biliary dysmorphogenesis. Hepatology 53:1959-1966

39. May-Simera HL, Kelley MW (2012) Cilia, Wnt signaling, and the cytoskeleton. Cilia 1:7

40. Benzing T, Simons M, Walz G (2007) Wnt signaling in polycystic kidney disease. J Am Soc Nephrol 18:1389-1398 
41. Neugebauer JM, Amack JD, Peterson AG, Bisgrove BW, Yost HJ (2009) FGF signalling during embryo development regulates cilia length in diverse epithelia. Nature 458:651-654

42. Hand NJ, Master ZR, Eauclaire SF, Weinblatt DE, Matthews RP, Friedman JR (2009) The microRNA-30 family is required for vertebrate hepatobiliary development. Gastroenterology 136 : 1081-1090

43. Sokol RJ, Shepherd RW, Superina R, Bezerra JA, Robuck P, Hoofnagle JH (2007) Screening and outcomes in biliary atresia: summary of a National Institutes of Health workshop. Hepatology 46:566-581

44. - Padgett KA, Lan RY, Leung PC, Lleo A, Dawson K, Pfeiff J, Mao TK, Coppel RL, Ansari AA, Gershwin ME (2009) Primary biliary cirrhosis is associated with altered hepatic microRNA expression. J Autoimmun 32:246-253. This is the first report of microRNA expression analyses used to identify dysregulated microRNAs and PBC.

45. Medina JF, Martinez A, Vazquez JJ, Prieto J (1997) Decreased anion exchanger 2 immunoreactivity in the liver of patients with primary biliary cirrhosis. Hepatology 25:12-17

46. Melero S, Spirli C, Zsembery A, Medina JF, Joplin RE, Duner E, Zuin M, Neuberger JM, Prieto J, Strazzabosco M (2002) Defective regulation of cholangiocyte $\mathrm{Cl}-/ \mathrm{HCO} 3(-)$ and $\mathrm{Na}+/$ $\mathrm{H}+$ exchanger activities in primary biliary cirrhosis. Hepatology 35:1513-1521

47. Banales JM, Arenas F, Rodriguez-Ortigosa CM, Saez E, Uriarte I, Doctor RB, Prieto J, Medina JF (2006) Bicarbonate-rich choleresis induced by secretin in normal rat is taurocholate-dependent and involves AE2 anion exchanger. Hepatology 43:266-275

48. Banales JM, Prieto J, Medina JF (2006) Cholangiocyte anion exchange and biliary bicarbonate excretion. World J Gastroenterol 12:3496-3511

49. - Banales JM, Saez E, Uriz M, Sarvide S, Urribarri AD, Splinter P, Tietz Bogert PS, Bujanda L, Prieto J, Medina JF, LaRusso NF (2012) Up-regulation of microRNA 506 leads to decreased Cl-/ $\mathrm{HCO}_{3}$ - anion exchanger 2 expression in biliary epithelium of patients with primary biliary cirrhosis. Hepatology 56:687-697. Determined that the upregulated microRNA, miR-506, targeted the chloride/bicarbonate exchanger, AE2, in PBC cholangiocytes; and suppression of miR-506 in isolated PBC cholangiocytes improves AE2 activity.

50. Qin B, Huang F, Liang Y, Yang Z, Zhong R (2013) Analysis of altered microRNA expression profiles in peripheral blood mononuclear cells from patients with primary biliary cirrhosis. J Gastroenterol Hepatol 28:543-550

51. Ninomiya M, Kondo Y, Funayama R, Nagashima T, Kogure T, Kakazu E, Kimura O, Ueno Y, Nakayama K, Shimosegawa T (2013) Distinct microRNAs expression profile in primary biliary cirrhosis and evaluation of miR 505-3p and miR197-3p as novel biomarkers. PLoS One 8:e66086

52. Aron JH, Bowlus CL (2009) The immunobiology of primary sclerosing cholangitis. Semin Immunopathol 31:383-397

53. Wiesner RH, Grambsch PM, Dickson ER, Ludwig J, MacCarty RL, Hunter EB, Fleming TR, Fisher LD, Beaver SJ, LaRusso NF (1989) Primary sclerosing cholangitis: natural history, prognostic factors and survival analysis. Hepatology 10:430-436

54. Bergquist A, Ekbom A, Olsson R, Kornfeldt D, Loof L, Danielsson A, Hultcrantz R, Lindgren S, Prytz H, Sandberg-Gertzen H, Almer S, Granath F, Broome U (2002) Hepatic and extrahepatic malignancies in primary sclerosing cholangitis. J Hepatol 36:321-327

55. Boberg KM, Bergquist A, Mitchell S, Pares A, Rosina F, Broome U, Chapman R, Fausa O, Egeland T, Rocca G, Schrumpf E (2002) Cholangiocarcinoma in primary sclerosing cholangitis: risk factors and clinical presentation. Scand $\mathrm{J}$ Gastroenterol 37:1205-1211
56. •• Li L, Masica D, Ishida M, Tomuleasa C, Umegaki S, Kalloo AN, Georgiades C, Singh VK, Khashab M, Amateau S, Li Z, Okolo P, Lennon AM, Saxena P, Geschwind JF, Schlachter T, Hong K, Pawlik TM, Canto M, Law J, Sharaiha R, Weiss CR, Thuluvath P, Goggins M, Shin EJ, Peng H, Kumbhari V, Hutfless S, Zhou L, Mezey E, Meltzer SJ, Karchin R, Selaru FM (2014) Human bile contains microRNA-laden extracellular vesicles that can be used for cholangiocarcinoma diagnosis. Hepatology. This study is the first to demonstrate that microRNAs from biliary exosomes hold great promise as diagnostic tools for CCA; a novel bile-based CCA diagnostic microRNA panel is presented.

57. Shigehara K, Yokomuro S, Ishibashi O, Mizuguchi Y, Arima Y, Kawahigashi Y, Kanda T, Akagi I, Tajiri T, Yoshida H, Takizawa T, Uchida E (2011) Real-time PCR-based analysis of the human bile microRNAome identifies miR-9 as a potential diagnostic biomarker for biliary tract cancer. PLoS One 6:e23584

58. Hartley JL, Davenport M, Kelly DA (2009) Biliary atresia. Lancet 374:1704-1713

59. Bezerra JA (2005) Potential etiologies of biliary atresia. Pediatr Transplant 9:646-651

60. - Hand NJ, Horner AM, Master ZR, Boateng LA, LeGuen C, Uvaydova M, Friedman JR (2012) MicroRNA profiling identifies miR-29 as a regulator of disease-associated pathways in experimental biliary atresia. J Pediatr Gastroenterol Nutr 54:186-192. A family of microRNAs dysregulated in the RRV model of BA was identified. Moreover, in vivo suppression of miR-29, using intraperitoneal injection of antisense oligonucleotides, resulted in a concomitant increase in predicted targets of this microRNA.

61. Roderburg C, Urban GW, Bettermann K, Vucur M, Zimmermann H, Schmidt S, Janssen J, Koppe C, Knolle P, Castoldi M, Tacke F, Trautwein C, Luedde T (2011) Micro-RNA profiling reveals a role for miR-29 in human and murine liver fibrosis. Hepatology 53:209-218

62. • Bessho K, Shanmukhappa K, Sheridan R, Shivakumar P, Mourya R, Walters S, Kaimal V, Dilbone E, Jegga AG, Bezerra JA (2013) Integrative genomics identifies candidate microRNAs for pathogenesis of experimental biliary atresia. BMC Syst Biol 7:104. An integrative genomics approach was used to reveal potential functional relevance of microRNAs and predicted targets in biliary atresia; provides information for further diagnostic and pathogenesis research.

63. Carvalho E, Liu C, Shivakumar P, Sabla G, Aronow B, Bezerra JA (2005) Analysis of the biliary transcriptome in experimental biliary atresia. Gastroenterology 129:713-717

64. Olnes MJ, Erlich R (2004) A review and update on cholangiocarcinoma. Oncology 66:167-179

65. Tabibian JH, Lindor KD (2012) Challenges of cholangiocarcinoma detection in patients with primary sclerosing cholangitis. J Anal Oncol 1:50-55

66. Lazaridis KN, Gores GJ (2006) Primary sclerosing cholangitis and cholangiocarcinoma. Semin Liver Dis 26:42-51

67. Aljiffry M, Walsh MJ, Molinari M (2009) Advances in diagnosis, treatment and palliation of cholangiocarcinoma: 1990-2009. World J Gastroenterol 15:4240-4262

68. Khan SA, Davidson BR, Goldin R, Pereira SP, Rosenberg WM, Taylor-Robinson SD, Thillainayagam AV, Thomas HC, Thursz MR, Wasan H (2002) Guidelines for the diagnosis and treatment of cholangiocarcinoma: consensus document. Gut 51(Suppl 6):VI1-9.

69. - McNally ME, Collins A, Wojcik SE, Liu J, Henry JC, Jiang J, Schmittgen T, Bloomston M (2013) Concomitant dysregulation of microRNAs miR-151-3p and miR-126 correlates with improved survival in resected cholangiocarcinoma. HPB (Oxford) 15:260-264. The authors demonstrated the prognostic value of two microRNAs form CCA tissues. 
70. Huang Q, Liu L, Liu CH, You H, Shao F, Xie F, Lin XS, Hu SY, Zhang $\mathrm{CH}$ (2013) MicroRNA-21 regulates the invasion and metastasis in cholangiocarcinoma and may be a potential biomarker for cancer prognosis. Asian Pac J Cancer Prev 14:829-834

71. Zahm AM, Hand NJ, Boateng LA, Friedman JR (2012) Circulating microRNA is a biomarker of biliary atresia. J Pediatr Gastroenterol Nutr 55:366-369

72. Krutzfeldt J, Kuwajima S, Braich R, Rajeev KG, Pena J, Tuschl T, Manoharan M, Stoffel M (2007) Specificity, duplex degradation and subcellular localization of antagomirs. Nucleic Acids Res 35:2885-2892

73. Krutzfeldt J, Rajewsky N, Braich R, Rajeev KG, Tuschl T, Manoharan M, Stoffel M (2005) Silencing of microRNAs in vivo with 'antagomirs'. Nature 438:685-689

74. Zhang Y, Wang Z, Gemeinhart RA (2013) Progress in microRNA delivery. J Control Release 172:962-974

75. Meng F, Henson R, Wehbe-Janek H, Smith H, Ueno Y, Patel T (2007) The MicroRNA let-7a modulates interleukin-6-dependent STAT-3 survival signaling in malignant human cholangiocytes. J Biol Chem 282:8256-8264

76. He Q, Cai L, Shuai L, Li D, Wang C, Liu Y, Li X, Li Z, Wang S (2013) Ars2 is overexpressed in human cholangiocarcinomas and its depletion increases PTEN and PDCD4 by decreasing MicroRNA-21. Mol Carcinog 52:286-296

77. Selaru FM, Olaru AV, Kan T, David S, Cheng Y, Mori Y, Yang J, Paun B, Jin Z, Agarwal R, Hamilton JP, Abraham J, Georgiades C, Alvarez H, Vivekanandan P, Yu W, Maitra A, Torbenson M, Thuluvath PJ, Gores GJ, LaRusso NF, Hruban R, Meltzer SJ (2009) MicroRNA-21 is overexpressed in human cholangiocarcinoma and regulates programmed cell death 4 and tissue inhibitor of metalloproteinase 3. Hepatology 49:1595-1601

78. Razumilava N, Bronk SF, Smoot RL, Fingas CD, Werneburg NW, Roberts LR, Mott JL (2012) miR-25 targets TNF-related apoptosis inducing ligand (TRAIL) death receptor-4 and promotes apoptosis resistance in cholangiocarcinoma. Hepatology $55: 465-475$
79. Zhang J, Han C, Wu T (2012) MicroRNA-26a promotes cholangiocarcinoma growth by activating beta-catenin. Gastroenterology 143(246-256):e248

80. Yang H, Li TW, Peng J, Tang X, Ko KS, Xia M, Aller MA (2011) A mouse model of cholestasis-associated cholangiocarcinoma and transcription factors involved in progression. Gastroenterology 141:378-388, 388 e371-374.

81. Zhong XY, Yu JH, Zhang WG, Wang ZD, Dong Q, Tai S, Cui YF, Li H (2012) MicroRNA-421 functions as an oncogenic miRNA in biliary tract cancer through down-regulating farnesoid $X$ receptor expression. Gene 493:44-51

82. Braconi C, Huang N, Patel T (2010) MicroRNA-dependent regulation of DNA methyltransferase-1 and tumor suppressor gene expression by interleukin-6 in human malignant cholangiocytes. Hepatology 51:881-890

83. Chen L, Yan HX, Yang W, Hu L, Yu LX, Liu Q, Li L, Huang DD, Ding J, Shen F, Zhou WP, Wu MC, Wang HY (2009) The role of microRNA expression pattern in human intrahepatic cholangiocarcinoma. J Hepatol 50:358-369

84. Meng F, Wehbe-Janek H, Henson R, Smith H, Patel T (2008) Epigenetic regulation of microRNA-370 by interleukin- 6 in malignant human cholangiocytes. Oncogene 27:378-386

85. Chen Y, Luo J, Tian R, Sun H, Zou S (2011) miR-373 negatively regulates methyl-CpG-binding domain protein 2 (MBD2) in hilar cholangiocarcinoma. Dig Dis Sci 56:1693-1701

86. Olaru AV, Ghiaur G, Yamanaka S, Luvsanjav D, An F, Popescu I, Alexandrescu S, Allen S, Pawlik TM, Torbenson M, Georgiades C, Roberts LR, Gores GJ, Ferguson-Smith A, Almeida MI, Calin GA, Mezey E, Selaru FM (2011) MicroRNA down-regulated in human cholangiocarcinoma control cell cycle through multiple targets involved in the G1/S checkpoint. Hepatology 54:2089-2098

87. Mott JL, Kobayashi S, Bronk SF, Gores GJ (2007) mir-29 regulates Mcl-1 protein expression and apoptosis. Oncogene 26:6133-6140 